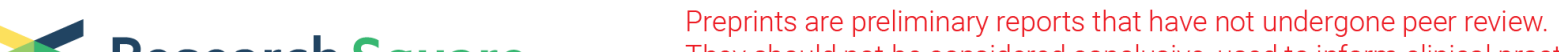 Research Square $\quad \begin{aligned} & \text { They should not be considered conclusive, used to inform clinical practice, } \\ & \text { or referenced by the media as validated information. }\end{aligned}$
}

\section{High expression of 5-hydroxymethylcytosine is associated with a more favorable hepatoblastoma prognosis in Chinese patients}

Junting Huang ( $\nabla$ huangjt@sysucc.org.cn )

Sun Yat-sen University Cancer Center https://orcid.org/0000-0002-2448-5837

Yang Hu

Sun Yat-sen University Cancer Center

Huadong Chen

Sun Yat-sen University First Affiliated Hospital

Binbin Chen

Sun Yat-sen University Cancer Center

Yu Zhang

Sun Yat-sen University Cancer Center

Shumei Yan

Sun Yat-sen University Cancer Center

Suying Lu

Sun Yat-sen University Cancer Center

Feifei Sun

Sun Yat-sen University Cancer Center

Jia Zhu

Sun Yat-sen University Cancer Center

Juan Wang

Sun Yat-sen University Cancer Center

Zijun Zhen

Sun Yat-sen University Cancer Center

Juncheng Liu

Sun Yat-sen University First Affiliated Hospital

Yizhuo Zhang

Sun Yat-sen University Cancer Center

\section{Research}

Keywords: Hepatoblastoma, pediatric, 5-hydroxymethylcytosine, immunohistochemistry, prognostic factors

Posted Date: October 18th, 2021 
DOl: https://doi.org/10.21203/rs.3.rs-961548/v1

License: (c) (i) This work is licensed under a Creative Commons Attribution 4.0 International License. Read Full License 


\section{Abstract \\ Background}

To analyze associations between the strength of expression of 5-hydroxymethylcytosine $(5 \mathrm{hmC})$ and survival outcomes of Chinese hepatoblastoma patients.

\section{Methods}

We collected and analyzed clinical data of hepatoblastoma patients aged $<15$ years treated at the Sun YatSen University Cancer Center or the First Affiliated Hospital of Sun Yat-sen University from Feb 2010 to Sept 2018. Patients were treated according to the Children's Oncology Group protocol. Specimens for pathology were collected by biopsy or surgical resection before initiation of chemotherapy. The level of expression of $5 \mathrm{hmC}$ was analyzed in tissue samples from 100 patients by immunohistochemistry. The prognostic value of $5 \mathrm{hmC}$ was evaluated by Cox regression and Kaplan-Meier analyses.

\section{Results}

We enrolled 100 patients with hepatoblastoma (median follow-up, 43.0 months; range, 18.4-131.6). The total recurrence rate was $30.0 \%$. Three-year overall survival (OS) rates of high and low $5 \mathrm{hmC}$ expressors was $92.6 \% \pm 3.6 \%$ and $80.3 \% \pm 5.9 \%$, respectively. Three-year event-free survival (EFS) of high and low expressors was $84.4 \% \pm 5.1 \%$ and $49.8 \% \pm 7.7 \%$, respectively. Thus, high levels of $5 \mathrm{hmC}$ expression are associated with more favorable OS and EFS. Multivariate analysis indicated that $5 \mathrm{hmC}$ expression level was an independent prognostic indicator for OS and EFS.

\section{Conclusions}

Our findings showed that strong hepatoblastoma $5 \mathrm{hmC}$ expression was associated with lower recurrence rates and longer EFS and OS. Thus, $5 \mathrm{hmC}$ expression may have prognostic relevance in hepatoblastoma.

\section{Background}

Hepatoblastoma $(\mathrm{HB})$ is the most common pediatric malignant tumor of the liver, accounting for nearly $80 \%$ of primary liver tumors in children [1]. With the rapid development of medical science and technology, therapeutic options for HB have been greatly improved. In the past 40 years, the overall survival (OS) rate of HB has increased from $30 \%$ to about $80 \%$ [2]. Accurate pathological diagnosis, classification and clinical staging are the main bases for formulating individual treatment plans and predicting the prognosis of children with $\mathrm{Hb}$ [3]. However, the prognosis of high-risk hepatoblastoma is still very poor, and 5-year OS is $54 \% \sim 58 \%[4,5]$. Therefore, new biomarkers are urgently needed to identify patients with a high risk of recurrence and/or poor survival. 
Epigenetics is a promising new field in cancer research, and DNA methylation is an important model for epigenetic characterization [6]. The detection of $5 \mathrm{hmC}$ represented a breakthrough in the field of epigenetics [7]. The conversion of 5-methylcytosine $(5 \mathrm{mC})$ to 5 -hydroxymethylcytosine $(5 \mathrm{hmC})$ is catalyzed by proteins encoded by the ten-eleven translocation (TET) gene family, which consists of TET1, -2 , and -3 [8, 9]. 5hmC is an intermediate residue in the process of active demethylation, which seems to be related to pluripotency maintenance and transcriptional activation of stem cells [10]. At present, the biological mechanism of action of $5 \mathrm{hmC}$ in cancer is still unclear. Liu et al. reported that $5 \mathrm{hmC}$ levels correlate positively with less aggressive tumor behavior in hepatocellular carcinoma [11].

In the present study, we applied immunohistochemical methods to retrospectively establish a correlation between $5 \mathrm{hmC}$ protein expression levels and clinical outcomes of hepatoblastoma. We studied the relationship between $5 \mathrm{hmC}$ and tumor history, clinicopathological characteristics (including age, gender, stage, OS and event-free survival (EFS)). We found that strong $5 \mathrm{hmC}$ protein expression was an independent favorable prognostic factor in children with hepatoblastoma.

\section{Patients And Methods}

\section{Ethics statement}

This research was approved by the Institutional Review Board (IRB) of Sun Yat-sen University Cancer Center (SYSUCC; Guangzhou, China), IRB number B2021-324-01. Written informed consent was obtained from each patient's parents involved in the study. All the original data are deposited at http://www.researchdata.org.cn.

\section{Patients and Specimens}

The patients included in this study were newly diagnosed as having HB at the SYSUCC and the First Affiliated Hospital of Sun Yat-sen University, between Feb 2010 and Sept 2018. The criteria for enrolling patients were as follows: 1) pathologically diagnosed as HB; 2) age less than 18 years; 3) tissue specimens obtained before initial treatment; 4) complete and detailed treatment process and follow-up data available. The specimens were obtained from HB patients by needle biopsy or open surgery. Chemotherapy regimens of different risk groups are shown in Supplementary Tables 1 and 2.

\section{Immunohistochemistry And Evaluation Criteria}

The tissue specimens were fixed in formalin and embedded in paraffin blocks, and then sectioned at a thickness of 4 um. Paraffin-embedded sections were deparaffinized in xylene and rehydrated with decreasing concentrations of alcohol. Next, slides were soaked in $3 \% \mathrm{H} 2 \mathrm{O} 2$ water for 30 minutes to block endogenous peroxidase activity and then blocked with 10\% FBS (Gibco; USA) for 1 hour to reduce nonspecific staining. Incubation with anti-5hmC rabbit mAb (1:10000, Active Motif, USA) followed at $4^{\circ} \mathrm{C}$ overnight. The sections were finally incubated with goat anti-rabbit secondary antibody (1:10000; ZSGB BIO, China) for 2 hours, dehydrated and sealed after visualization with DAB (ZSGB BIO). 
The immunohistochemical staining results were evaluated according to the intensity of staining and the proportion of tumor cells with an unequivocal positive reaction. The intensity was scored as follows: 0 , negative; 1 , weak; 2 , moderate; and 3 , strong. The frequency of positive cells was defined as follows: 0 , less than $5 \% ; 1,5-25 \% ; 2,26-50 \% ; 3,51-75 \%$; and 4 , greater than $75 \%$. The composite score is the product of these two scores. Composite scores of 0 to 5 were considered to indicate low or negative expression, and 6 to 12 were taken as strong expression. A fluorescence microscope(Olympus BX61, Japan)was employed for image acquisition. Scoring was done independently by two pathologists.

\section{Follow Up}

After treatment, patients were reviewed and followed up regularly. Monitoring included alpha-fetoprotein (AFP), whole blood routine, biochemical routine, electrocardiogram, echocardiogram, chest and abdomen CT. The last follow-up time was on $23 \mathrm{rd} \mathrm{Dec}, 2020$ and the median observation time was 43 months. OS was defined at the endpoint of the study as the period from the date of initial diagnosis to death or the last follow-up. EFS was defined as the period from the date of initial diagnosis to the occurrence of an event or the last follow-up. The occurrence of an event included disease recurrence, progressive disease, death, or diagnosis of a second malignant neoplasm.

\section{Statistical analysis}

All data analyses were performed using SPSS software (version 25.0, SPSS Company, Chicago, Illinois, USA). OS and EFS were calculated by the Kaplan-Meier method and compared using the log-rank test. Prognostic factors predicting OS and EFS were assessed by multivariate Cox proportional hazards regression analyses. All covariates that had clinical significance were included in a multivariate Cox proportional hazards model. Results are given as mean \pm S.D. All statistical tests were two-sided, and $\mathrm{P}<$ 0.05 was taken to indicate a significant difference.

\section{Results}

\section{Immunohistochemical Characteristics}

Typical examples of immunohistochemical staining are shown in Figure 1. We observed 5hmC staining mainly of the nuclei of tumor cells and hepatocytes, with very little cytoplasmic staining.

\section{Baseline Characteristics}

A total of 157 patients diagnosed with $\mathrm{HB}$ was identified during the study period. Based on our inclusion criteria, 57 patients were excluded because no tissue specimens before initial treatment were available for $37(23.6 \%)$, complete and detailed treatment process data were not available for $14(8.9 \%)$, and the remaining 6 were lost to follow-up (3.8\%). The patients' baseline characteristics are summarized in Table 1. A total of 100 patients was finally included in the study, $63 \%$ being male and $37 \%$ female, with a median age 
at diagnosis of 20.0 months (range, $0.9-107.0$ months). AFP was elevated $(>1000 \mathrm{ng} / \mathrm{mL}$ ) in $92 \%$ of patients. Based on the results of the imaging studies, patients were classified using the PRETEXT staging system. Twenty patients had distant metastasis, 17 had vascular invasion and 6 had tumor rupture at diagnosis. Fetal histology $(n=32)$ was the most common pathological subtype in our patients according to postoperative pathology results. All patients were classified using the The Children's Oncology Group (COG) risk group scale. Using the COG risk stratification system, zero patients were considered as being very lowrisk, 9 as low-risk, 52 as intermediate-risk, and 39 as high-risk. There were $545 \mathrm{hmC}^{\text {High }}$ and $465 \mathrm{hmclow}$ patients. Correlations of $5 \mathrm{hmC}$ expression with clinicopathologic characteristics are shown in Table 1. 
Table 1

Characteristics of patients included in the study

\section{Clinicopathological indexes}

\begin{tabular}{|c|c|c|c|c|}
\hline & & 5-hmclow & 5-hmC high & $P$ \\
\hline \multirow[t]{2}{*}{ Gender } & Male & 29 & 34 & 0.993 \\
\hline & Female & 17 & 20 & \\
\hline \multirow[t]{2}{*}{ Age(months) } & $凶 36$ & 30 & 40 & 0.335 \\
\hline & $\geq 36$ & 16 & 14 & \\
\hline \multirow[t]{2}{*}{ AFP at diagnosis $(\mathrm{ng} / \mathrm{mL})$} & $\leq 1000$ & 2 & 6 & 0.214 \\
\hline & $\nabla 1000$ & 44 & 48 & \\
\hline \multirow[t]{4}{*}{ PRETEXT staging } & I & 4 & 5 & 0.842 \\
\hline & II & 23 & 30 & \\
\hline & III & 9 & 7 & \\
\hline & IV & 10 & 12 & \\
\hline \multirow[t]{2}{*}{ Metastasis at diagnosis } & No & 37 & 43 & 0.920 \\
\hline & Yes & 9 & 11 & \\
\hline \multirow[t]{2}{*}{ Vascular Invasion } & Absent & 42 & 41 & 0.041 \\
\hline & Present & 4 & 13 & \\
\hline \multirow[t]{2}{*}{ Tumor Rupture } & No & 44 & 50 & 0.521 \\
\hline & Yes & 2 & 4 & \\
\hline \multirow[t]{8}{*}{ Histological subtype } & Epithelial & 2 & 4 & 0.420 \\
\hline & Fetal(Pure Fetal excluded) & 11 & 19 & \\
\hline & Pure Fetal & 0 & 2 & \\
\hline & Embryonal & 4 & 2 & \\
\hline & Mixed embryonal-fetal & 9 & 5 & \\
\hline & Mixed epithelial-mesenchymal & 7 & 11 & \\
\hline & macrotrabecular & 1 & 1 & \\
\hline & HB (unkown) & 12 & 10 & \\
\hline \multirow[t]{2}{*}{ COG risk group } & Very low risk & 0 & 0 & 0.380 \\
\hline & Low risk & 6 & 3 & \\
\hline
\end{tabular}




\begin{tabular}{|llll|}
\hline Clinicopathological indexes & & No. of patients \\
\hline & Intermediate risk & 24 & 28 \\
\hline & High risk & 16 & 23 \\
\hline
\end{tabular}

\section{Survival}

The median follow-up period was 43.2 months (range, 18.4-131.6 months). The 1- and 3-year OS of the 100 investigated patients was $94.0 \pm 0.24$ and $86.9 \pm 0.34 \%$, respectively. The median OS was 40.4 months. The 1and 3-year DFS was $84.0 \pm 0.50 \%$ and $67.9 \pm 0.37 \%$, respectively. The median DFS was 33.3 months. The difference between patients with $5 \mathrm{hmC}^{\mathrm{High}}$ and $5 \mathrm{hmC}^{\text {low }}$ was statistically significant for both $\mathrm{OS}(\mathrm{P}=0.044$, Figure $2 a)$ and DFS $(P<0.001$, Figure $2 b)$.

\section{Univariate And Multivariate Analysis Of Prognostic Factors}

All factors listed in Table 1 were included in univariate analyses (Table 2), of which age at diagnosis (OS $92.7 \%$ vs $73.3 \% \mathrm{P}=0.010$, DFS $75.2 \%$ vs $50.1 \% \mathrm{P}=0.011$ ), PRETEXT staging (OS $95.0 \%$ vs $73.3 \% \mathrm{P}=0.005$, DFS $80.5 \%$ vs $47.8 \% P=0.001$ ), metastasis at diagnosis (OS $92.3 \%$ vs $65.0 \% P=0.001$, DFS $73.2 \%$ vs $48.1 \%$ $\mathrm{P}=0.032$ ), COG risk group (OS $98.2 \%$ vs $69.2 \% \mathrm{P}<0.001$, DFS $82.2 \%$ vs $45.2 \% \mathrm{P}<0.001$ ) and $5 \mathrm{hmC}$ expression level (OS $92.6 \%$ vs $80.3 \% \mathrm{P}=0.044$, DFS $84.7 \%$ vs $49.8 \% \mathrm{P}<0.001$ ) were identified as significant prognostic factors for clinical outcome. Multivariate analyses showed that of these factors, age at diagnosis (HR 3.293, 95\% $\mathrm{Cl}$ 0.966-11.224, $\mathrm{P}=0.057$ ), COG risk group (HR 8.661, 95\% $\mathrm{Cl} 1.332-56.299, \mathrm{P}<0.001$ ) and $5 \mathrm{hmC}$ expression level (HR 0.230, 95\% Cl 0.068-0.781, $\mathrm{P}=0.044$ ) were independent prognostic factors for OS (Table 2). For DFS, multivariate analysis showed that only COG risk group (HR 4.387, 95\% Cl 1.577-12.202, $\mathrm{P}<0.001)$ and $5 \mathrm{hmC}$ expression ( $\mathrm{HR} 0.197,95 \% \mathrm{Cl} 0.085-0.458, \mathrm{P}<0.001)$ were independent prognostic factors (Table 2). 
Table 2

Univariate analysis and multivariate analyses of 5-hmC expression associated with survival and recurrence

\begin{tabular}{|c|c|c|c|c|c|c|c|c|}
\hline & \multicolumn{4}{|c|}{ Overall survival } & \multicolumn{4}{|c|}{ Event-free survival } \\
\hline & $\begin{array}{l}\text { Univariate } \\
P\end{array}$ & $\begin{array}{l}\text { Hazard } \\
\text { ratio }\end{array}$ & $95 \% \mathrm{Cl}$ & $\mathrm{P}$ & $\begin{array}{l}\text { Univariate } \\
\mathrm{P}\end{array}$ & $\begin{array}{l}\text { Hazard } \\
\text { ratio }\end{array}$ & $95 \% \mathrm{Cl}$ & $P$ \\
\hline Gender & 0.645 & & & NA & 0.918 & & & NA \\
\hline $\begin{array}{l}\text { Age at } \\
\text { diagnosis( }(36 \\
\text { months vs. } \geq 36 \\
\text { months) }\end{array}$ & 0.010 & 3.293 & $\begin{array}{l}0.966- \\
11.224\end{array}$ & 0.057 & 0.011 & & & NS \\
\hline $\begin{array}{l}\text { AFP }(\leq 1000 \\
\text { vs. } \otimes 1000)\end{array}$ & 0.268 & & & NA & 0.298 & & & NA \\
\hline $\begin{array}{l}\text { PRETEXT } \\
\text { staging(I/II vs. } \\
\text { III/IV })\end{array}$ & 0.005 & & & NS & 0.001 & & & NS \\
\hline $\begin{array}{l}\text { Metastasis(Yes } \\
\text { vs. No) }\end{array}$ & 0.001 & & & NS & 0.032 & & & NS \\
\hline $\begin{array}{l}\text { Vascular } \\
\text { Invasion(Absent } \\
\text { vs. Present) }\end{array}$ & 0.032 & & & NS & 0.259 & & & NA \\
\hline $\begin{array}{l}\text { Tumor } \\
\text { Rupture(Yes vs. } \\
\text { No) }\end{array}$ & 0.338 & & & NA & 0.605 & & & NA \\
\hline $\begin{array}{l}\text { COG risk } \\
\text { group(Low/ } \\
\text { Intermediate vs. } \\
\text { high) }\end{array}$ & $\varangle 0.001$ & 8.661 & $\begin{array}{l}1.332- \\
56.299\end{array}$ & 0.024 & $\llbracket 0.001$ & 4.387 & $\begin{array}{l}1.577- \\
12.202\end{array}$ & $\otimes 0.001$ \\
\hline $\begin{array}{l}\text { 5-hmC } \\
\text { expression } \\
\text { (high vs. low) }\end{array}$ & 0.044 & 0.230 & $\begin{array}{l}0.068- \\
0.781\end{array}$ & 0.018 & 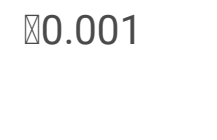 & 0.197 & $\begin{array}{l}0.085- \\
0.458\end{array}$ & $\varangle 0.001$ \\
\hline
\end{tabular}

\section{Discussion}

At present, there are few data on the relationship between $5 \mathrm{hmC}$ and hepatoblastoma prognosis. In this study, we explored the relationship between the level of expression of $5 \mathrm{hmC}$ by immunohistochemistry and the clinical features and prognosis of 100 cases of hepatoblastoma. We investigated recognized clinical prognostic factors (diagnostic age, gender, AFP level, etc.) and factors used for risk classification (PRETEXT stage, metastasis, vascular invasion, tumor rupture, etc.) [12]. Other variables have low prognostic value and were therefore ignored. This study is limited to patients in a single center, which may introduce bias. We found that the level of expression of tumor $5 \mathrm{hmC}$ was not correlated with gender, age, AFP level at diagnosis, PRETEXT stage, metastasis, histological subtype or COG risk group. However, in univariate and multivariate analysis, the expression of $5 \mathrm{hmC}$ was identified as an independent prognostic factor. This suggests that the expression of $5 \mathrm{hmC}$ may be a powerful prognostic factor in hepatoblastoma. 
Thus far, a large number of studies has reported a relationship between $5 \mathrm{hmC}$ and several different tumors (malignant melanoma, cervical squamous cell carcinoma, non-small cell lung cancer, etc.) [13-16]. Usually, $5 \mathrm{hmC}$ is mainly present in embryonic stem cells and adult neural cells. In hepatocellular carcinoma, the expression of $5 \mathrm{hmC}$ was reported to be lower than in the surrounding normal tissues $[17,18]$. It was also reported that in adult cancer, lower TET expression can reduce the level of $5 \mathrm{hmC}$ in solid and hematopoietic tumors $[9,13,19,20]$. However, the activity of these enzymes in pediatric tumors has rarely been established. Studies have shown that that $5 \mathrm{hmC}$ profiles are prognostic for the outcome of neuroblastoma $[21,22]$. Rivas et al. reported increased expression of the TET gene in hepatoblastoma [23]. Animal models indicated that overexpression of TET inhibited differentiation during embryonic development $[9,20,24,25]$. It is speculated that the up regulation of TET in hepatoblastoma indicates that liver differentiation is blocked, which is consistent with the long-suggested hypothesis that inhibiting the differentiation pathway of organ stem cells leads to embryonic tumorigenesis. The increase of $5 \mathrm{hmC}$ content in these tumors confirms the functional role of the observed TET overexpression. Although the previous study of Rivas et al. assessed the expression of $5 \mathrm{hmC}$ in archived hepatoblastoma tissues, the number of cases was limited and lacked further validation [23]. Our study is the largest analysis of $5 \mathrm{hmC}$ protein expression in hepatoblastoma.

The main limitation of this work at present is its retrospective nature. However, it is worth noting that this is a sample of children with hepatoblastoma in China. Hepatoma is a rare tumor with a low incidence rate, and to the best of our knowledge the present study is the first to report the significance of $5 \mathrm{hmC}$ expression for hepatoma prognosis. Our results show that high expression of $5 \mathrm{hmC}$ predicts relatively less invasive tumor behavior. Importantly, $5 \mathrm{hmC}$ expression enables us to more accurately predict the true prognosis of patients with hepatoblastoma. It is worth noting that $5 \mathrm{hmC}$ can be measured using a simple technique (immunohistochemistry), so it can be carried out in any reasonably equipped clinical pathology laboratory; also, the antibody is a commercially-available monoclonal, so it should produce robust and reproducible results. Additionally, the scoring system is simple and the consistency between observers is good.

Histopathologists can easily use the same sections for diagnostic evaluation. All these features increase the opportunity to translate this biomarker into clinical application. A scoring system based on image analysis is possible and can make scoring easier, but it is not easy for histopathologists because they review cases under a microscope and increase the complexity of biomarker translation.

Future work will need to accurately determine how $5 \mathrm{hmC}$ should be used. In particular, it will be important to assess whether combination with other biomarkers and with clinicopathological features can increase accuracy of prediction. However, this requires a much larger study. Ideally, thousands of cases will eventually form a statistical prediction model, at which time the prognostic scoring system of new cases will need to be externally verified. The present study provides strong support for exploring this approach. In addition, the epigenetics of $5 \mathrm{hmC}$ may help to classify hepatoblastoma risk and guide clinical targeted treatment strategies in the future.

\section{Conclusion}


In this cohort of Chinese children with hepatoblastoma, higher $5 \mathrm{hmC}$ levels correlated with less aggressive tumor behavior. Low $5 \mathrm{hmC}$ expression was associated with lower OS rates and higher cumulative recurrence rates. $5 \mathrm{hmC}$ expression may have prognostic relevance in hepatoblastoma.

\section{Abbreviations}

Abbreviation

$5 \mathrm{hmC}$

OS

EFS

HB

TET

IRB

SYSUCC

AFP

COG

\section{meaning}

\section{5-hydroxymethylcytosine}

overall survival

event-free survival

Hepatoblastoma

ten-eleven translocation

Institutional Review Board

Sun Yat-sen University Cancer Center

alpha-fetoprotein

The Children's Oncology Group

\section{Declarations}

\section{Funding}

The authors declare no funding.

\section{Conflicts of interest/Competing interests}

The authors declare no conflict of interest.

\section{Availability of data and material}

All original data were deposited online http://www.researchdata.org.cn.

\section{Consent for publication}

Patients' legal guardians have signed informed consent regarding publishing their data and photographs.

\section{Authors' contributions}

All authors contributed to the study conception and design. Material preparation, data collection and analysis were performed by Junting Huang, Yang Hu, Huadong Chen. The first draft of the manuscript was 
written by Junting Huang and all authors commented on previous versions of the manuscript. All authors read and approved the final manuscript.

\section{Ethics approval}

The study was approved by the Review Board (IRB) of Sun Yat-sen University Cancer Center.

\section{Consent to participate}

Informed consent was obtained from legal guardians.

\section{Acknowledgements}

The authors would like to thank the children and their families for agreeing to participate in the study, and Li Zhang for developing the study database.The authors would also like to express their gratitude to EditSprings (https://www.editsprings.cn/) for the expert linguistic services provided.

\section{References}

1. Spector LG, Birch J. The epidemiology of hepatoblastoma. PEDIATR BLOOD CANCER. 2012;59:776-9.

2. Czauderna P, Lopez-Terrada D, Hiyama E, Haberle B, Malogolowkin MH, Meyers RL. Hepatoblastoma state of the art: Pathology, genetics, risk stratification, and chemotherapy. CURR OPIN PEDIATR. 2014;26:19-28.

3. Maibach R, Roebuck D, Brugieres L, Capra M, Brock P, Dall'Igna P, Otte JB, De Camargo B, Zsiros J, Zimmermann A, Aronson D, Childs M, Scopinaro M, Morland B, Plaschkes J, Czauderna P, Perilongo G. Prognostic stratification for children with hepatoblastoma: The SIOPEL experience. EUR J CANCER. 2012;48:1543-9.

4. Huang J, Hu Y, Jiang H, Xu Y, Lu S, Sun F, Zhu J, Wang J, Sun X, Liu J, Zhen Z, Zhang Y. CHIC risk stratification system for predicting the survival of children with hepatoblastoma: Data from children with hepatoblastoma in china. FRONT ONCOL. 2020;10:552079.

5. Haberle B, Maxwell R, Schweinitz DV, Schmid I. High Dose Chemotherapy with Autologous Stem Cell Transplantation in Hepatoblastoma does not Improve Outcome. Results of the GPOH Study HB99. KLIN PADIATR. 2019;231:283-90.

6. Rodriguez-Paredes M, Esteller M. Cancer epigenetics reaches mainstream oncology. NAT MED. 2011;17:330-9.

7. Tahiliani M, Koh KP, Shen Y, Pastor WA, Bandukwala H, Brudno Y, Agarwal S, lyer LM, Liu DR, Aravind L, Rao A. Conversion of 5-methylcytosine to 5-hydroxymethylcytosine in mammalian DNA by MLL partner TET1. SCIENCE. 2009;324:930-5.

8. Wu H, Zhang Y. Mechanisms and functions of Tet protein-mediated 5-methylcytosine oxidation. Genes Dev. 2011;25:2436-52.

9. Rasmussen KD, Helin K. Role of TET enzymes in DNA methylation, development, and cancer. Genes Dev. 2016;30:733-50. 
10. Ko M, Bandukwala HS, An J, Lamperti ED, Thompson EC, Hastie R, Tsangaratou A, Rajewsky K, Koralov SB, Rao A. Ten-Eleven-Translocation 2 (TET2) negatively regulates homeostasis and differentiation of hematopoietic stem cells in mice. Proc Natl Acad Sci U S A. 2011;108:14566-71.

11. Liu WR, Tian MX, Jin L, Yang LX, Ding ZB, Shen YH, Peng YF, Zhou J, Qiu SJ, Dai Z, Fan J, Shi YH. High expression of 5-hydroxymethylcytosine and isocitrate dehydrogenase 2 is associated with favorable prognosis after curative resection of hepatocellular carcinoma. J Exp Clin Cancer Res. 2014;33:32.

12. Meyers RL, Maibach R, Hiyama E, Haberle B, Krailo M, Rangaswami A, Aronson DC, Malogolowkin MH, Perilongo G, von Schweinitz D, Ansari M, Lopez-Terrada D, Tanaka Y, Alaggio R, Leuschner I, Hishiki T, Schmid I, Watanabe K, Yoshimura K, Feng Y, Rinaldi E, Saraceno D, Derosa M, Czauderna P. Riskstratified staging in paediatric hepatoblastoma: A unified analysis from the Children's Hepatic tumors International Collaboration. LANCET ONCOL. 2017;18:122-31.

13. Lian CG, Xu Y, Ceol C, Wu F, Larson A, Dresser K, Xu W, Tan L, Hu Y, Zhan Q, Lee CW, Hu D, Lian BQ, Kleffel S, Yang Y, Neiswender J, Khorasani AJ, Fang R, Lezcano C, Duncan LM, Scolyer RA, Thompson JF, Kakavand H, Houvras Y, Zon LI, Mihm MJ, Kaiser UB, Schatton T, Woda BA, Murphy GF, Shi YG. Loss of 5-hydroxymethylcytosine is an epigenetic hallmark of melanoma. CELL. 2012;150:1135-46.

14. Saldanha G, Joshi K, Lawes K, Bamford M, Moosa F, Teo KW, Pringle JH. 5-Hydroxymethylcytosine is an independent predictor of survival in malignant melanoma. Mod Pathol. 2017;30:60-8.

15. Zhang LY, Han CS, Li PL, Zhang XC. 5-Hydroxymethylcytosine expression is associated with poor survival in cervical squamous cell carcinoma. JPN J CLIN ONCOL. 2016;46:427-34.

16. Liao Y, Gu J, Wu Y, Long X, Ge DI, Xu J, Ding J. Low level of 5-Hydroxymethylcytosine predicts poor prognosis in non-small cell lung cancer. ONCOL LETT. 2016;11:3753-60.

17. Yang H, Liu Y, Bai F, Zhang JY, Ma SH, Liu J, Xu ZD, Zhu HG, Ling ZQ, Ye D, Guan KL, Xiong Y. Tumor development is associated with decrease of TET gene expression and 5-methylcytosine hydroxylation. ONCOGENE. 2013;32:663-9.

18. Pfeifer GP, Kadam S, Jin SG. 5-Hydroxymethylcytosine and its potential roles in development and cancer. Epigenetics Chromatin. 2013;6:10.

19. Liu C, Liu L, Chen X, Shen J, Shan J, Xu Y, Yang Z, Wu L, Xia F, Bie P, Cui Y, Bian XW, Qian C. Decrease of 5-hydroxymethylcytosine is associated with progression of hepatocellular carcinoma through downregulation of TET1. PLOS ONE. 2013;8:e62828.

20. Rawluszko-Wieczorek AA, Siera A, Jagodzinski PP. TET proteins in cancer: Current 'state of the art'. Crit Rev Oncol Hematol. 2015;96:425-36.

21. Applebaum MA, Barr EK, Karpus J, West-Szymanski DC, Oliva M, Sokol EA, Zhang S, Zhang Z, Zhang W, Chlenski A, Salwen HR, Wilkinson E, Dobratic M, Grossman RL, Godley LA, Stranger BE, He C, Cohn SL. 5-Hydroxymethylcytosine profiles in circulating Cell-Free DNA associate with disease burden in children with neuroblastoma. CLIN CANCER RES. 2020;26:1309-17.

22. Applebaum MA, Barr EK, Karpus J, Nie J, Zhang Z, Armstrong AE, Uppal S, Sukhanova M, Zhang W, Chlenski A, Salwen HR, Wilkinson E, Dobratic M, Grossman R, Godley LA, Stranger BE, He C, Cohn SL. 5Hydroxymethylcytosine profiles are prognostic of outcome in neuroblastoma and reveal transcriptional networks that correlate with tumor phenotype. JCO Precis Oncol 2019;3. 
23. Rivas MP, Aguiar T, Fernandes GR, Caires-Junior LC, Goulart E, Telles-Silva KA, Cypriano M, de Toledo S, Rosenberg C, Carraro DM, Da CC, Da Cl, Krepischi A. TET upregulation leads to 5-Hydroxymethylation enrichment in hepatoblastoma. FRONT GENET. 2019;10:553.

24. Bagci $\mathrm{H}$, Fisher AG. DNA demethylation in pluripotency and reprogramming: The role of tet proteins and cell division. CELL STEM CELL. 2013;13:265-9.

25. Ito S, D'Alessio AC, Taranova OV, Hong K, Sowers LC, Zhang Y. Role of Tet proteins in $5 \mathrm{mC}$ to $5 \mathrm{hmC}$ conversion, ES-cell self-renewal and inner cell mass specification. NATURE. 2010;466:1129-33.

\section{Figures}

\section{$5 \mathrm{hmC}$ high expression}

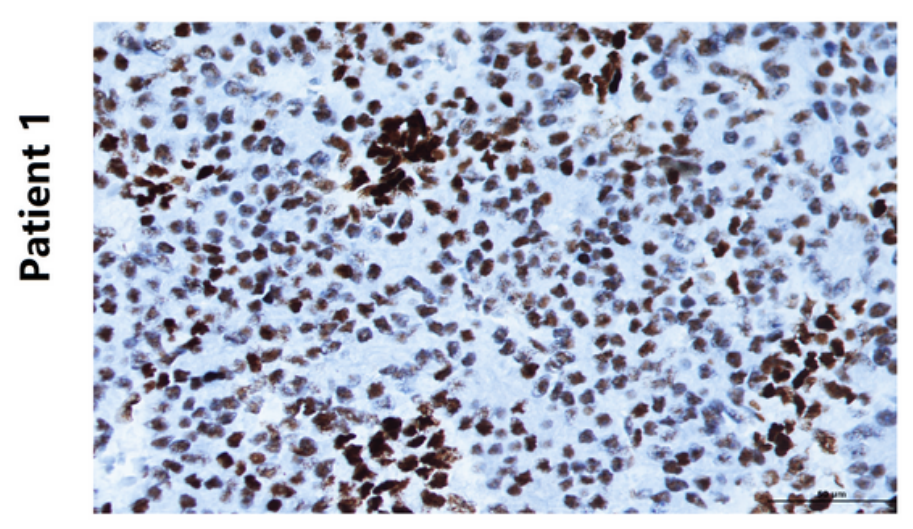

5hmC high expression

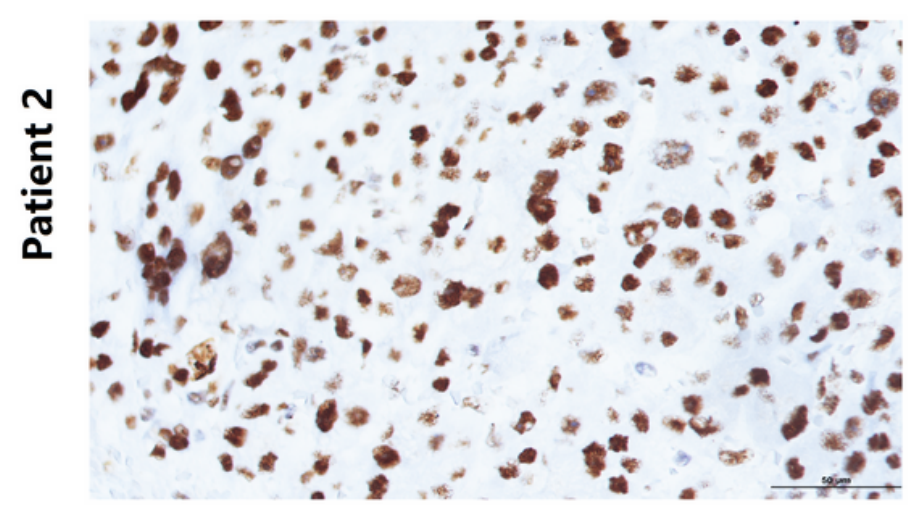

\section{$5 \mathrm{hmC}$ low expression}

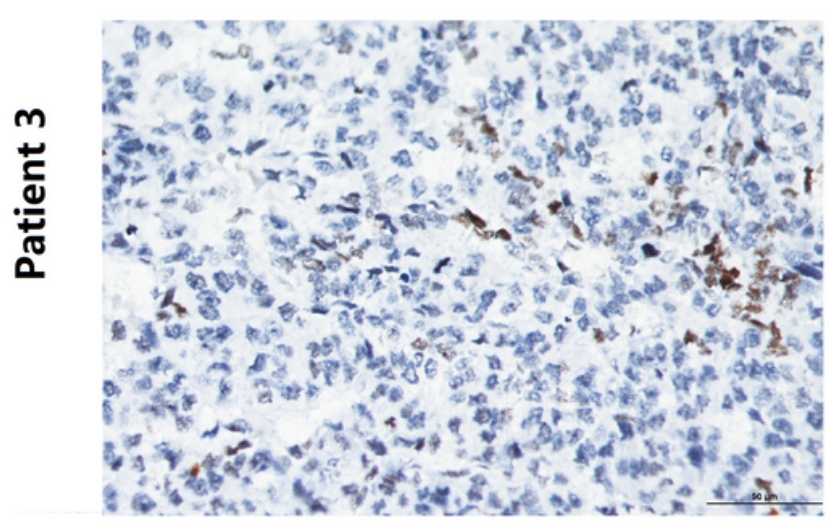

$5 \mathrm{hmC}$ low expression

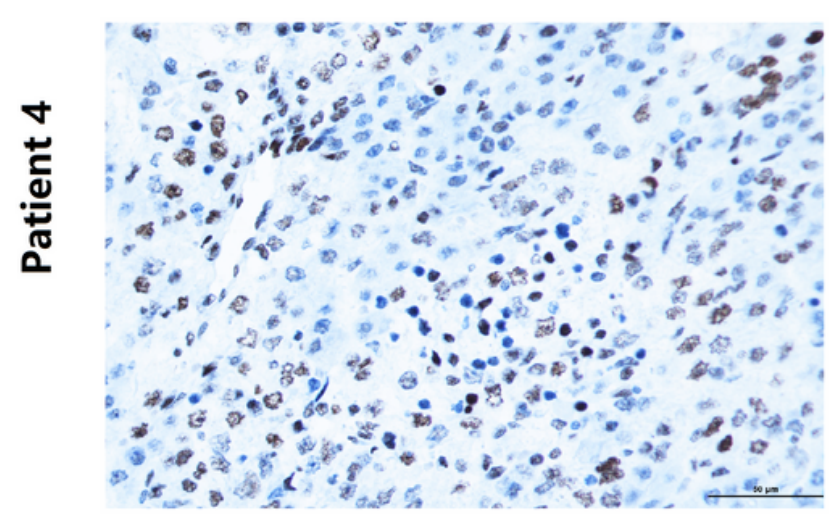

Figure 1

Typical picture of $\mathrm{IHC}$ analysis in $\mathrm{HB}$ tissue with different $5 \mathrm{hmC}$ expression levels. (scale bar, $50 \mu \mathrm{m}$ ) 
a

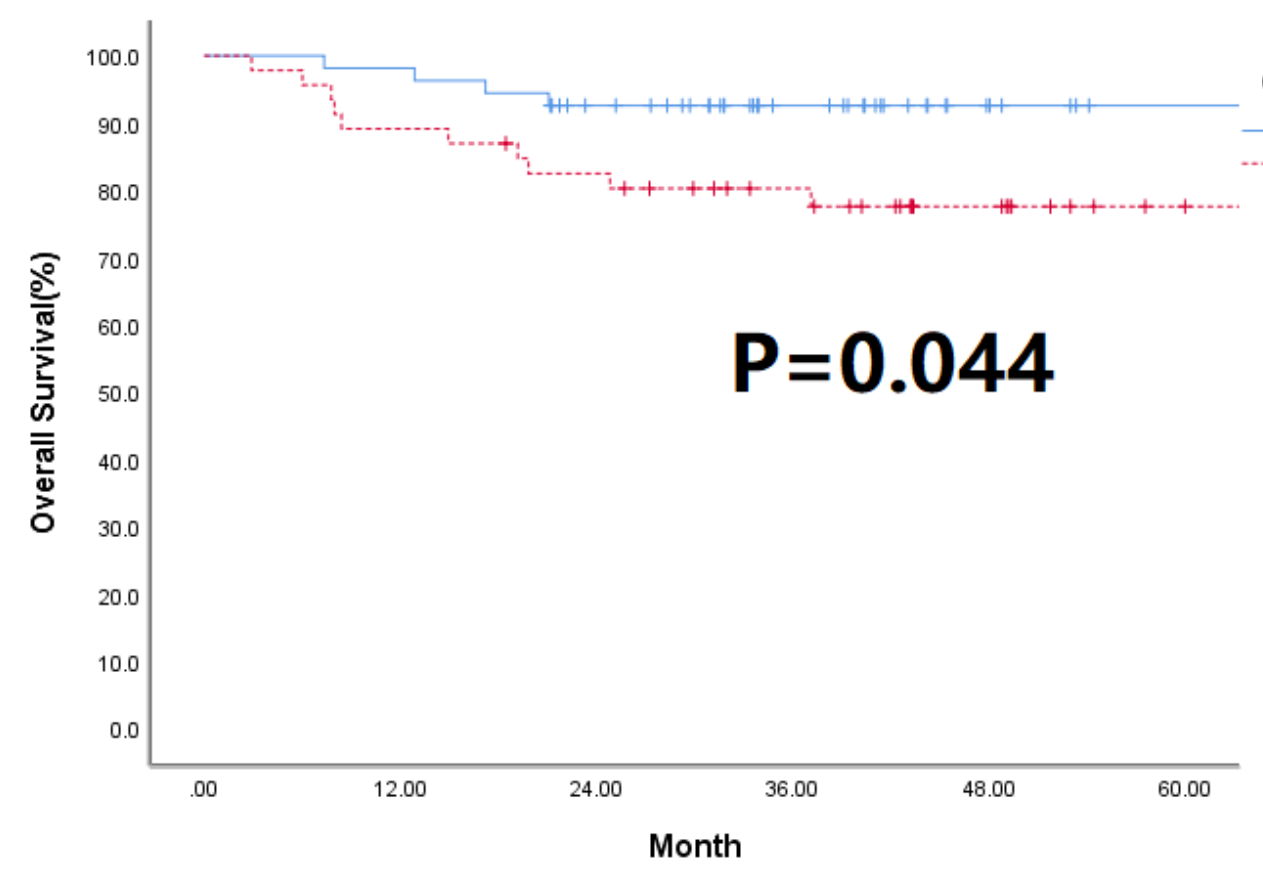

b

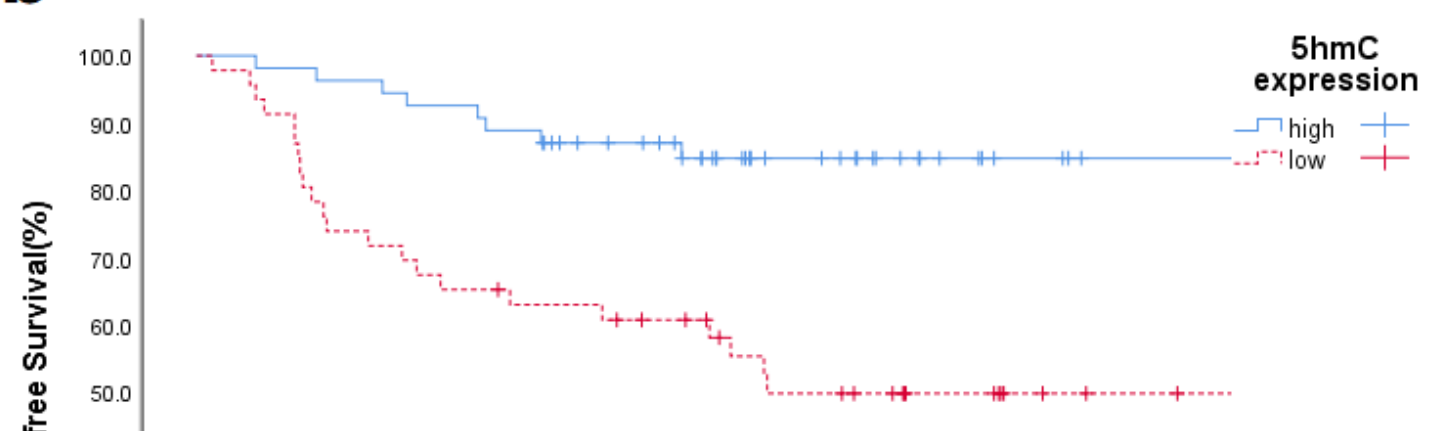

$P<0.001$

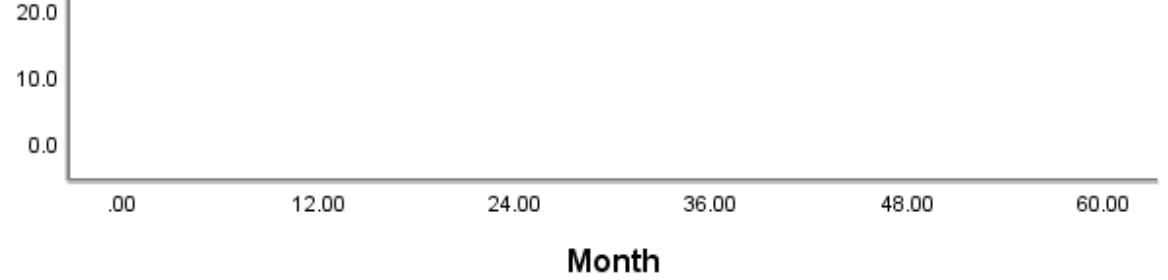

Figure 2

Kaplan-Meier survival curves about OS(a) and DFS(b) in 100 HB patients expressing different $5 \mathrm{hmC}$ levels

\section{Supplementary Files}

This is a list of supplementary files associated with this preprint. Click to download. 
- SupplementaryTable1.docx

- SupplementaryTable2.docx 